\title{
ATIVIDADES FÍSICAS E O CORPO NA CONCEPÇÃO DE GRADUANDOS DE EDUCAÇÃO FÍSICA: UMA ANÁLISE DAS PRÁTICAS CORPORAIS DE UNIVERSITÁRIOS DA REGIÃO DE LIMEIRA
}

Joacir Rogge Mugnaini

\section{Resumo}

Este trabalho está focado em analisar as concepções que estudantes do curso de Educação Física têm sobre o corpo, sobre as atividades físicas e a Educação Física na escola. Constituíram-se como objetivo deste estudo caracterizar e identificar a concepção de estudantes de Educação Física sobre o corpo e a prática de atividades físicas, verificar os motivos que levam os alunos do curso de Educação Física a praticar atividades físicas e analisar as concepções dos entrevistados sobre a Educação Física na escola.

Neste sentido, foram feitas entrevistas de grupo com alunos de três diferentes classes de um curso de Licenciatura em Educação Física. Estes grupos se constituíram de homens e mulheres que cursavam o primeiro, o terceiro e o quinto semestre do curso.

\section{Palavras-Chave}

Educação Física; Corpo; Escola

\section{PHYSICAL ACTIVITIES AND THE BODY IN THE CONCEPTION OF GRADUATED OF PHYSICAL EDUCATION: AN ANALYSIS OF PRACTICAL THE CORPORAL ONES OF COLLEGES STUDENT OF THE REGION OF LIMEIRA}

Joacir Rogge Mugnaini

\begin{abstract}
This paper is focus on analyzing the conceptions that students of Physical Education course have about the body, the physical activities and the Physical Education in the school.

It is defined as objective of this study to characterize and identify the conception of Physical Education students about body and the practice of physical activities, to check the reasons that Physical Education students have to practice physical activities and to analyze the conceptions of the interviewed ones about Physical Education in the school.

Therein, group interviews were done with students of three different classrooms in the course of Physical Education Bachelor. These groups were constituted by men and women who attended classes in the first, third and fifth semester of the course.
\end{abstract}

\section{Key-Words}

Physical Education; Body; School 


\section{INTRODUÇÃO}

No meu trabalho como professor de Educação Física, observei que as pessoas desenvolvem diferentes conceitos e pré-conceitos relacionados ao corpo e às práticas a ele relacionadas. Estas diferenças se tornam evidentes, por exemplo, na forma como alunos de uma aula de Educação Física na escola demonstram níveis diferenciados de interesse por determinada atividade proposta pelo professor. Percebi também que os motivos que os levam para as academias ou para os clubes em busca desta prática corporal estão diretamente associados a valores estéticos, a busca da saúde ou a necessidade de convivência social.

Diante disso, procurei desenvolver uma pesquisa no sentido de verificar como estas tendências estão presentes nos estudantes de um curso de Educação Física buscando os seguintes objetivos:

\section{OBJETIVO GERAL}

Analisar as concepções que estudantes do curso de Educação Física têm sobre o corpo, atividades físicas e a Educação Física na escola.

\section{OBJETIVOS ESPECÍFICOS}

- Caracterizar e identificar a concepção de estudantes de Educação Física sobre o corpo e a prática de atividades físicas;

- Verificar os motivos que levam os alunos do curso de Educação Física a praticar atividades corporais

- Analisar as concepções dos entrevistados sobre a Educação Física na escola.

\section{PROCEDIMENTOS METODOLÓGICOS}

Este estudo se caracteriza como qualitativo. O procedimento empregado para a coleta dos depoimentos dos grupos de alunos do curso de Educação Física foi o grupo focal.

O estudo através de grupo focal se desenvolveu por meio da coleta e análise do discurso de participantes de grupos específicos através da verbalização de seus valores e de suas experiências dentro dos temas destacados no projeto. Está diretamente relacionado com os procedimentos empregados para a coleta de dados e sua forma de organização seguiu os mesmos princípios.

A técnica de pesquisa utilizada para trabalhar com as entrevistas foi a de análise de conteúdo conforme proposto por Bardin, (1977). 
Os dados coletados nas entrevistas foram analisados a partir de categorias que emergiram do próprio material e relacionados com a bibliografia pesquisada.

Foram definidas algumas categorias para análise das entrevistas.

A primeira categoria estudou a concepção de corpo e de prática de atividades físicas. A partir desta percepção buscamos identificar se os entrevistados praticavam algum tipo de atividade física regular e quais seriam os motivos que os levavam a isto.

Na segunda categoria, foram analisadas respectivamente, a Educação Física praticada e a Educação Física esperada na escola pelos entrevistados.

\section{A EDUCAÇ̃̃O FÍSICA ESCOLAR NO BRASIL}

\section{A EDUCAÇÃO FÍSICA ESCOLAR DE 1920 A 1960}

A idéia que parece ter influenciado e determinado muitos dos fundamentos da Educação Física, entre as décadas de 30 e 40, foi a "eugenia". Segundo Betti (1991), a eugenia difundia o ideal de melhoria e aperfeiçoamento da "raça brasileira" que poderia ser alcançado através da prática constante e sistemática de atividades físicas, entre outras ações. A Liga Brasileira de Hygiene Mental (LBHM) foi uma das principais divulgadoras destes ideais.

Os valores eugênicos foram influenciados por Francis Galton que, na Inglaterra, no final do século XIX, definia a eugenia como o estudo de fatores físicos e mentais, socialmente controláveis, no sentido de alterar as qualidades racionais, visando o bem estar da espécie.

Para Betti apud Domingues, 1991, estabeleceu-se uma diferença substancial entre eugenia e eutecnia, ao considerar que a eugenia agiria sobre a espécie promovendo a seleção dos mais bem dotados, visando o melhoramento genético e impedindo a geração de tipos considerados inferiores enquanto a eutecnia constituir-se- ia de medidas de ordem exterior, estimulando o desenvolvimento de heranças biológicas por meio de medidas como a higiene, a educação física e moral.

O ensino secundário, durante o governo Vargas, recebeu grande ênfase, principalmente com a finalidade de se trabalhar com uma faixa etária em que os alunos passariam por um processo de transformações físicas e psicológicas e, portanto, propícia a fixação de valores. A Educação Física foi incluída neste processo como elemento facilitador específico para a solidificação destes objetivos. 
E clara, neste período, a relação entre a Educação Física e o sistema militar. O resultado desta influência é que o "Método Francês" foi adotado como oficial para as escolas secundárias em 1931, por meio da Portaria $\mathrm{n}^{\circ} 70$ de 30/06/1031. Tal método havia sido desenvolvido pela escola de "Joinville-le-Pont" da França, e possuía conotações claramente militares. Não por acaso, esse método de trabalho nas aulas de Educação Física foi usado até os anos 50.

A partir da década de 50 o esporte começa a fazer parte importante das aulas de Educação Física e, em 1955, pela Portaria n 104 e 06\04\1955, criava-se os Centros de Educação Física que oficializava o vínculo da Educação Física com o esporte. (DA COSTA, 2006).

\section{A EDUCAÇÃO FÍSICA NAS DÉCADAS DE 1960 E 1970}

Nessa época a Educação Física foi definida, conforme a Portaria n 148 do Mec de 1967, como: "um conjunto de ginásticas, jogos, desportos, danças e recreação" cujos objetivos constituíam-se em "desenvolver harmoniosamente o corpo e o espírito, fortalecer a vontade, formar e disciplinar para hábitos sadios, adquirir habilidades, equilibrar e conservar a saúde e incentivar o espírito de equipe".

Neste período, o conceito anátomo-fisiológico, que se baseava em valores predominantemente biológicos de treinamento do corpo, visando uma melhoria na performance e o aperfeiçoamento do gesto esportivo, orientava a concepção de Educação Física. Os questionamentos ao conceito anátomofisiológico responsabilizavam os exercícios formais de promoverem o desinteresse das crianças pela Educação Física. O conceito bio-sócio-psico-físico acabou sendo incorporado pelo Decreto 58.130 de 1966, que definia, para a Educação Física, o objetivo de "aproveitar e dirigir as forças do indivíduo físicas, morais, intelectuais e sociais, de maneira a utilizá-las na sua totalidade".

Neste contexto, o esporte acaba ocupando um papel importante nas aulas de Educação Física e é tido como um elemento capaz de atingir alguns objetivos definidos para a disciplina. O Método Desportivo Generalizado, como observa Betti (1991), representou uma reação contra os velhos métodos de ginástica e, ao mesmo tempo, foi uma tentativa de manter o esporte, já uma instituição social autônoma, sob o domínio pedagógico da Educação Física, e de impedir uma completa esportização da disciplina. As aulas de Educação Física, então passaram a abordar tanto os conteúdos tradicionais como as modalidades esportivas.

Assim, durante o regime militar, através do Decreto 69.450 de 1971, o governo estabeleceu que "a Educação Física desportiva e recreativa deve ser integrada como atividade escolar regular o currículo dos 
cursos de todos os graus de ensino". A Educação Física foi definida, então, como "atividade que por seus meios, processos e técnicas, desenvolve e aprimora forças físicas, morais, cívicas, psíquicas e sociais do educando".

A Educação Física passa, assim a ser utilizada de acordo com a ideologia dominante da época, marcada pela necessidade de manutenção de uma ordem política, atrelando-a ao fenômeno do esporte de competição que era amplamente utilizado como forma de propaganda de regimes de governos, caracterizada, principalmente, pela grande competitividade desenvolvida neste período, entre o bloco socialista da "cortina de ferro" e os países capitalistas liderados pelos Estados Unidos.

\section{A EDUCAÇÃO FÍSICA NA DÉCADA DE 1980}

Um grande trabalho de reflexão sobre a real efetividade da Educação Física na escola passou a ser realizado a partir dos anos 80 . A necessidade de se promover essa reflexão acentua-se após o término do regime militar, época em que os exercícios físicos e o esporte serviam, claramente, a uma ideologia tecnicista e militarista.

Parece que as transformações ocorridas na sociedade brasileira a partir do final do regime militar e, na esfera internacional, com o declínio da polarização entre o mundo capitalista e socialista, refletiram também sobre a área da Educação Física. Segundo Caparroz (2005), os anos de 1980 configuram-se como o nascimento de concepções e práticas pedagógicas libertadoras, transformadoras, na perspectiva de desenvolver uma Educação Física voltada para o ser humano e não mais para as necessidades do capital.

Segundo as Diretrizes Gerais para a Educação Física (BRASIL, 1981), a Educação Física Escolar tem "um fim em si mesma", e mostra-se como "um conjunto de atividades educativas que visam a criar o gosto e o hábito do exercício físico regular". Dentro dessa concepção, deveria ser trabalhada com os seguintes objetivos:

Segundo Betti (1991), neste período, foi proposta uma nova regulamentação oficial para a Educação Física Escolar, com a introdução de novos conceitos e objetivos, os quais referiam-se aos domínios psicomotor, cognitivo e afetivo, em função das peculiaridades e necessidades da clientela. Da $1^{\circ}$ a $4^{\circ}$ séries, a ênfase devia ser dada à educação psicomotora, da $5^{\circ}$ a $8^{\circ}$ séries, aos desenvolvimentos das qualidades físicas básicas e à iniciação nas habilidades esportivas e, no $2^{\circ}$ grau, às atividades que 
contribuam para o aperfeiçoamento de todas as potencialidades físicas, morais e psíquicas do aluno, numa clara preferência por um modelo de subsistemas, no sentido de integrar a prática da Educação Física ao processo educacional.

Uma das principais propostas enfatizadas neste período foi a abordagem desenvolvimentista e a educação psicomotora, norteada pelo desenvolvimento motor e fundamentada na psicologia. Essa abordagem é semelhante à concepção de Educação Física crítica e progressista que buscava no seu trabalho as discussões presentes na educação brasileira.

As discussões críticas da educação nacional apresentaram propostas mais voltadas ao fator cultural e social da Educação Física como agente transformador. São elas: a Educação física crítico-superadora e a crítico-emancipatória, estas sim podem ser consideradas teorias progressistas da Educação Física. Caparroz (2005) afirma que a produção dos anos 80 trouxe à tona questões importantes no campo filosófico, sociológico, pedagógico, provavelmente obscurecidas nas décadas anteriores, em função da hegemonia da influência médica e biológica sobre a área.

\section{AS CONCEPÇÕES ATUAIS DA EDUCAÇÃO FÍSICA ESCOLAR NO BRASIL}

Nas últimas duas décadas, a Educação Física Escolar adotou novas posturas em relação à implementação do desenvolvimento corporal dos alunos do ensino básico (fundamental e médio). A Educação Física, que até então se baseava em conteúdos esportivos e buscava, basicamente, formar o aluno para a competição através da performance esportiva, a partir da década de 90 começa a adotar uma outra postura, propondo a utilização das atividades corporais como o próprio esporte, a dança, as lutas e a ginástica sob a égide de proporcionar a saúde física, psíquica e social da população estudantil.

A atuação da Educação Física passou por uma redefinição com a Lei de Diretrizes e Bases da Educação n 9394 de 1996, uma vez que, nela, a disciplina passa e ser considerada componente curricular, dentro de uma estrutura em que os principais objetivos deixam de ser a simples transmissão de conteúdos e passam a buscar a formação integral do aluno como ser humano participativo na sua sociedade e dono de uma cultura específica.

Passa-se agora a utilizar as diversas modalidades esportivas com a finalidade de desenvolver a cooperação, o respeito aos companheiros e às regras, principalmente como forma de integração do aluno dentro do grupo em que se encontre inserido. Os Parâmetros Curriculares Nacionais do Ensino Médio 
(BRASIL, 1999, p. 159) por exemplo, define que o esporte deve encontrar seu lugar na escola através de uma proposta que atinja a todos os alunos envolvidos com as aulas de Educação Física, isto é, que seja uma ferramenta de inclusão e não de exclusão do aluno.

A contextualização dos temas da Educação Física como a alimentação, o sedentarismo, a prevenção de doenças, entre outras também passou a ser elemento importante do trabalho do professor. Cabe ao mesmo identificar problemas relacionados a sua área de trabalho e desenvolvê-los em suas aulas.

\section{A EDUCAÇÃO FÍSICA E AS QUESTÕES DO CORPO NA SOCIEDADE}

Para Pereira (1988), a cultura física é caracterizada como uma atividade de lazer determinada por fatores econômicos num meio onde o lucro acaba sendo um dos determinantes das relações sociais. Quem é rico torna-se parâmetro de sucesso. Para se ter acesso à prática desta cultura existe um valor a ser pago sob a forma de material esportivo e mensalidades de clubes e de academias. Tudo está relacionado ao dinheiro. Como observa Bracht (1999), na forma como o homem produz e reproduz a vida, o corpo sofre uma ação, ou seja, sofre intervenções com a finalidade de se adaptar às exigências das formas sociais de organização da vida. Enquanto alvo das necessidades produtivas (corpo produtivo), das necessidades sanitárias (corpo saudável), das necessidades morais (corpo deserotizado) e das necessidades de adaptação e controle social (corpo dócil). Neste sentido, o corpo precisa ser educado, uma vez que a educação corporal é educação do comportamento que, por sua vez, não é corporal e sim humano. Educar o comportamento corporal é educar o comportamento humano.

Hoje, como nunca na história, o corpo humano tem sido objeto de pesquisas, e explorado pela mídia no sentido de promover o consumo de produtos especialmente desenvolvidos para proporcionar vigor físico, saúde e simetria corporal. Esta cultura da valorização do corpo tem estimulado a produção de uma grande quantidade de informações, de equipamentos, de pesquisas e induzido a população à mudança de hábitos alimentares e físicos em função de novos valores relacionados ao corpo.

\section{A EdUCAÇÃO Física E OS VALORES ESTÉticos ESTABELECIDOS PARA O CORPO}

Um dos grandes problemas relacionados ao corpo, atualmente disseminados principalmente pelos meios de comunicação e pelos interesses comerciais, está ligado aos padrões estéticos estabelecidos como ideais. 
$\mathrm{Na}$ sociedade moderna, influenciada pelo consumismo pragmático, a cultura da estética corporal tem sido um dos principais alvos do comércio e do lucro incentivados, ora pela necessidade de construir um corpo moldado em função dos padrões vigentes, ora pela busca da saúde. O que está claro é que em nenhum outro momento histórico o corpo foi tão valorizado, comercializado, consumido e tratado como hoje.

Diante disso, pode-se afirmar que, valores estéticos também estão presentes na observação dos corpos, mas poderiam ser confundidos com um tipo de estética imposta. Seria assim, uma pseudo-estética difundida pelos meios de comunicação para promover o consumo de dietas, tratamentos e outras atividades especialmente desenvolvidos para gerar lucro. Baudrillard (1991) afirma, ainda, que "o corpo encontra-se estreitamente vinculado às finalidades de produção enquanto suporte (econômico), como princípio de integração (psicológica) dirigida do indivíduo e à maneira de estratégia (política) de controle social".

\section{A EDUCAÇÃO FÍSICA E A PROMOÇ̃̃O DA SAÚDE}

Quando trazemos o conceito de saúde para dentro da escola e, mais especificamente, como um tema importante a ser trabalhado pela Educação Física naquele ambiente, percebemos que também neste contexto, a atual definição para o termo acaba por provocar ou exigir mudanças de posturas e de ações nas atividades desenvolvidas pelo componente curricular. A Educação Física, baseada em conceitos de rendimento ou calcada nas atividades esportivas já não satisfaz as carências de informações necessárias para atingir um nível de qualidade de vida priorizado hoje pela sociedade e pelos objetivos estabelecidos para a educação como um todo.

No âmbito da Educação Física escolar atual ocorre um certo dualismo de opiniões quanto ao grau de importância que as questões da saúde devem receber dentro de seus conteúdos. Entre os principais autores da área existe certa divergência em relação ao assunto. Marques e Gaya (1999) identificam autores como Faria Junior e Nahas, como favoráveis à estratégia de relacionar a Educação Física à performance desportiva e à promoção da saúde. Também Nahas (1992) e Guedes e Guedes (1997) defendem as relações entre Educação Física e saúde justificando-se pela premissa de que existe forte associação entre aptidão física e o bom funcionamento orgânico com a diminuição da incidência de algumas doenças. 
Por outro lado, Ferreira (1997), desenvolve uma crítica a Educação Física referenciada pela área da saúde, classificando-a como de viés biologicista propondo que os saberes da Educação Física foram e devem ser construídos a partir de uma dialética entre orgânico-fisiológico e o histótico-cultural, indicando assim estudos baseados na antropologia, na filosofia e na sociologia para se atingir outras visões interdisciplinares de movimento humano.

Pelo exposto aqui, é possível afirmar que a Educação Física deve atuar como uma área de conhecimento comprometida com o desenvolvimento e com a manutenção do relacionamento entre o ser humano completo com a sociedade. Em qualquer dessas situações, a partir do conceito atual de qualidade de vida, estamos falando da utilização da Educação Física como agente da promoção da saúde, porém, de forma muito mais abrangente, pois esta atitude se reverte numa mudança de valores e de posições que, provavelmente, não será assimilada a curto prazo.

\section{ANÁLISE DAS ENTREVISTAS}

\section{A CONCEPÇÃO DE CORPO E DE PRÁTICA DE ATIVIDADES FÍSICAS PARA O GRUPO 01}

A grande maioria dos entrevistados do grupo estabeleceu uma relação entre a cultura corporal da sociedade com os valores estéticos estabelecidos.

As citações acima refletem a preocupação dos entrevistados em vincular a Educação Física como promotora da saúde corporal, algumas vezes presa a padrões estéticos, outras vezes, não.

\section{A CONCEPÇÃO DE CORPO E DE PRÁTICA DE ATIVIDADES FÍSICAS PARA O GRUPO 02}

Nesta categoria, o grupo 02, não aborda a saúde e a convivência social de forma significativa, como objetivos da prática de atividades físicas, dando nos discursos de seus componentes, uma ênfase muito maior à crítica aos valores estéticos e à influência negativa da mídia em relação ao uso das atividades físicas e outros recursos, para atingir padrões corporais estabelecidos.

\section{A CONCEPÇÃO DE CORPO E DE PRÁTICA DE ATIVIDADES FÍSICAS PARA O GRUPO 03}

Os entrevistados consideram os meios de comunicação como propagadores de valores deturpados sobre o corpo e que, basicamente, é a busca pelos padrões estéticos estabelecidos que motivam as pessoas a praticarem atividades físicas. Nesta crítica social, os entrevistados culpam os interesses econômicos das empresas de estimular determinadas atitudes em relação ao corpo por parte da população com a finalidade de obter lucro. 


\section{A PRÁTICA DE ATIVIDADES FÍSICAS PELOS ENTREVISTADOS DO GRUPO 01}

Os depoimentos revelam que, enquanto os alunos entrevistados justificam a atividade física praticada por eles com objetivos específicos de saúde, convivência social e por gostar de determinados tipos de atividades ou esportes, o motivo que leva as pessoas de forma geral a procurar praticar atividades é como forma de atingir padrões estéticos.

\section{A PRÁTICA DE ATIVIDADES FÍSICAS PELOS ENTREVISTADOS DO GRUPO 02}

$\mathrm{O}$ discurso dos alunos entrevistados nesse grupo estabelecem uma diferenciação entre os motivos que levam as pessoas, em geral, à prática de atividades e os motivos próprios, ou seja, enquanto para esses alunos, as pessoas são influenciadas pela mídia e pelos padrões estabelecidos, os seus motivos estão mais baseados na saúde e na convivência social.

\section{A PRÁTICA DE ATIVIDAdeS FÍSICAS PELOS ENTREVISTADOS DO GRUPO 03}

Nesta categoria, o discurso dos componentes do grupo focaram-se, principalmente, em questões relacionadas à saúde física e psicológica e na interação com a sociedade como justificativa para a prática individual de atividades física. Notamos que a estética e o gosto pela prática não ocupou nenhum espaço nos depoimentos. Percebeu-se também que as atividades esportivas foram as mais citadas nesta categoria.

\section{A EDUCAÇÃO FÍSICA PRATICADA NA ESCOLA PELO GRUPO 01}

De acordo com as declarações, a Educação Física na escola ainda está presa a valores e costumes que são considerados ultrapassados pelos discursos atuais, principalmente no que se refere ao modo de se trabalhar com o esporte e com a diferenciação entre gêneros nas aulas.

\section{A EDUCAÇÃO FÍSICA PRATICADA NA ESCOLA PELO GRUPO 02}

A crítica à postura dos professores do ensino básico aparece em alguns dos discursos, especificamente relacionadas às aulas nas quais o trabalho dos professores não era sentida por parte dos alunos entrevistados.

\section{A EDUCAÇÃO FÍSICA PRATICADA NA ESCOLA PELO GRUPO 03}

De acordo com os depoimentos acima podemos verificar também que as modalidades esportivas estiveram presentes como elementos centrais nas aulas de Educação Física dos alunos deste grupo. 


\section{A EDUCAÇÃO FÍSICA ESPERADA NA ESCOLA PELO GRUPO 01}

Os alunos do grupo 01, de forma geral, demonstraram grande preocupação em assumir uma postura diferenciada como profissionais. Porém, também demonstraram uma certa falta de informação sobre a estrutura e características de seu curso, fato que pode ser justificado até mesmo por estarem iniciando seu curso superior. Suas expectativas para a área se revelaram muito boas baseadas na busca e transmissão de informações e conhecimentos.

\section{A EDUCAÇÃO FÍSICA ESPERADA NA ESCOLA PELO GRUPO 02}

Parece que a concepção dos alunos deste grupo sobre como a Educação Física deve ser desenvolvida nas aulas é diferente da do grupo anterior, no sentido que seus componentes já dominam algumas informações sobre a estrutura de uma aula e deixam transparecer seus conceitos sobre a Educação Física com mais clareza principalmente quando associam diferentes objetivos da Educação Física na escola, bem como diferentes modos de trabalhá-los nas aulas.

\section{A EDUCAÇÃO FÍSICA ESPERADA NA ESCOLA PELO GRUPO 03}

Eles pontuam que, uma aula de Educação Física deve abordar a recreação, promover o desenvolvimento e uma melhoria de vida. Nesse sentido as suas falas apontam para a importância da educação física escolar visar o aumento da auto-estima , a inclusão social e incentivar a pratica de esportes.

Os alunos procuram também definir um padrão atitudinal para o próprio profissional da Educação Física na escola. A postura do professor de Educação Física foi abordada sob a forma de descrição de propostas para desenvolver o seu trabalho na escola.

\section{CONSIDERAÇÕES FINAIS}

Quando realizamos a revisão bibliográfica sobre a Educação Física escolar no Brasil, ficou evidente que as propostas adotadas pela mesma normalmente estavam ligadas a outros fatores como o contexto político e econômico. Mesmo com as grandes mudanças de abordagens experimentadas nas últimas décadas pela Educação Física, percebeu-se que, cada forma de propor o trabalho com o corpo estava vinculada a determinados valores e conceitos biológicos, históricos ou culturais.

As entrevistas revelaram também a permanência de tais valores nas práticas vivenciadas pelos entrevistados na escola uma vez que, segundo eles, predomina ainda algumas modalidades esportivas como principal componente das aulas, reforçando assim uma cultura que se firmou na escola nas últimas décadas da utilização da Educação Física para a formação de atletas e de um momento

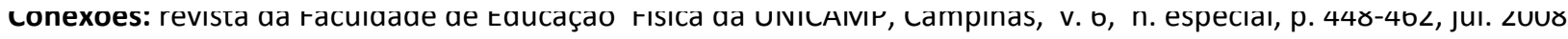
ISSN: $1983-9030$ 
especificamente dedicado a prática esportiva.

O professor de Educação Física também foi cobrado, nas conversas realizadas, quanto à sua postura e organização das atividades práticas e teóricas. Segundo os depoimentos de muitos entrevistados, o professor, mesmo dominando os conceitos e conhecimentos da área, acabou cedendo seu espaço diante de uma tendência mais poderosa caracterizada pela cultura esportiva e pela busca dos resultados em competições.

Parece que, a forma como a Educação Física ainda tem sido tratada na escola acaba por influenciar o modo como alunos e alunas entendem e participam das aulas. Foram muitos os depoimentos que relataram uma participação diferenciada entre meninos e meninas nas aulas de Educação Física escolar quando a mesma era baseada em competições esportivas. Não estou insinuando que o esporte seja excludente. Creio que o problema da exclusão se potencializa quando as atividades são direcionadas para os mais adaptados aos gestos esportivos. E neste caso a exclusão não se limita apenas ao gênero, mas a outros grupos inseridos na escola.

Os alunos entrevistados apresentaram posições bastante críticas em relação a Educação Física e sua atuação na escola. Os discursos, principalmente dos concluintes do curso, demonstraram uma tendência à transformação do modo como o corpo é tratado no ambiente escolar. Acredito porém, que o problema da Educação Física esteja na resistência que a própria sociedade impõem no sentido de dar continuidade ao modelo atual de trabalho com o corpo na escola.

Devo frisar que, os depoimentos se focaram basicamente no sistema público de ensino básico, que recebe a maior parcela da população e trabalha com alunos provindos das famílias de menor poder econômico. Este fator também se torna importante na medida em que analisamos interesses políticos e sociais ligados à formação educacional destes alunos. Não coube, porém, realizar tal análise neste momento, pois teríamos que extrapolar o limite da Educação Física como foco do trabalho.

Creio que o grande desafio da Educação Física escolar hoje está em transformar as expectativas nela depositadas ao longo de sua história e que foram se confundindo com a cultura corporal e esportiva do país, influenciada e mantida pelos interesses econômicos e políticos que têm utilizado o corpo como meio de obter lucro e poder. 
Educação Física não é sinônimo de esporte. O esporte pode ser um meio utilizado para se obter algo muito mais abrangente, assim como a dança, o jogo e outras atividades. Cabe à Educação Física na escola organizar e transmitir conhecimentos e práticas, vivências e experiências, valores e conceitos para atingir um de seus objetivos históricos que é superar uma antiga mas presente dicotomia entre corpo e mente. Ensinar, na escola, as novas gerações a respeitarem esta relação, a se respeitarem como corpos e a respeitarem seus semelhantes.

Esta é a grande contribuição que a Educação Física pode trazer para a sociedade.

\section{REFERÊNCIAS}

BARDIN, L. Análise de conteúdo. Lisboa: Edições 70, 1977.

BAUDRILLARD, J. A sociedade de consumo. Rio de Janeiro: Elfos, 1991.

BETTI, M. Educação Física e sociedade. São Paulo: Movimento, 1991.

BRACHT, V. A constituição das teorias pedagógicas da Educação Física. Cadernos CEDES , Campinas, v. 19, n. 48, 1999.

BRASIL. Portaria $n^{\circ} 70,1931$

BRASIL. Ministério da Educação e Cultura. Decreto nº 67.450, Brasília, 1971.

BRASIL. Congresso Nacional. Lei de diretrizes e bases da Educação. Brasília, 1978.

BRASIL. Ministério da Educação e Cultura. Secretaria de Educação e Esportes. Diretrizes gerais para a Educação Física. Brasília, 1981

BRASIL. Congresso Nacional. Lei de diretrizes e bases da educação. Brasília, 1996.

BRASIL. Ministério da Educação. Parâmetros Curriculares Nacionais do Ensino Médio. Brasília, 1999

CAPARROZ, F. E. Entre a Educação Física na escola e a educação Física da escola: a Educação Física como componente curricular. Campinas: Autores Associados, 2005.

DACOSTA, L. Atlas do Esporte no Brasil, Rio de Janeiro: Confef, 2006.

FERREIRA, M. G. Crítica a uma proposta de Educação Física direcionada a promoção da saúde a partir do referencial da sociologia do currículo e da pedagogia crítico-superadora. Revista Movimento, v. 4, n. 7, p 21-33, 1997

GUEDES, D. P.; GUEDES, J. E. R. P. Características dos programas de Educação Física escolar. Revista Paulista de Educação Física. São Paulo, v. 11, n . 1, p. 49-62, 1997

MARQUES, A. T.; GAYA, A. Atividade física, aptidão física e educação para a saúde: estudos na área pedagógica em Portugal e no Brasil. Revista Paulista de Educação Física, São Paulo, v. 13, n. 1, p. 83- 
103, jan./jun. 1999

NAHAS, M. V.; CORBIN, C. B. Educação para a aptidão física e a saúde. Revista Brasileira deCiência e Movimento, São Paulo, v. 6, n. 3, p. 14-24, 1992

PEREIRA, F. M. Dialética da cultura física: introdução à crítica da Educação Física, do esporte e da recreação. São Paulo: Ícone, 1988. 


\section{Joacir Rogge Mugnaini}

\section{Faculdades Integradas Einstein de Limeira}

\section{Referência do artigo:}

\section{ABNT}

MUGNAINI, J. R. Atividades físicas e o corpo na concepção de graduandos de educação física: uma análise das práticas corporais de universitários da região de Limeira. Conexões, v. 6, p. 448-462, 2008.

\section{APA}

Mugnaini, J. R. (2008) Atividades físicas e o corpo na concepção de graduandos de educação física: uma análise das práticas corporais de universitários da região de Limeira. Conexões, 6, 448-462.

\section{VANCOUVER}

Mugnaini JR. Atividades físicas e o corpo na concepção de graduandos de educação física: uma análise das práticas corporais de universitários da região de Limeira. Conexões, 2008; 6: 448-462. 